\title{
ENFRENTAMENTO DE MULHERES QUE VIVENCIARAM O CÂNCER DE MAMA
}

\section{FACING WOMEN WHO LIVED BREAST CANCER}

\section{ENFRENTAMIENTO DE MUJERES QUE VIVIENDO EL CÁNCER DE MAMA}

\author{
Ana Paula Alonso Reis ${ }^{1}$, Marislei Sanches Panobianco ${ }^{2}$, Clícia Valim Côrtes Gradim ${ }^{3}$.
}

\section{RESUMO}

Objetivo: conhecer as mulheres que recebem o diagnóstico do câncer de mama. Método: Estudo qualitativo que utilizou, como referencial teórico, o Interacionismo Simbólico e como metodológico, a Teoria Fundamentada em Dados. Foram entrevistadas treze mulheres em quimioterapia, de um município mineiro, no mês de janeiro de 2014 e, após a análise, surgiu a teoria "Para vivenciar o câncer de mama é necessário que haja um enfrentamento". Resultados: a metodologia permitiu a discussão em três categorias para debate da teoria, sendo elas: recebendo a notícia do diagnóstico e da necessidade dos tratamentos; adaptação ao tratamento; experiências anteriores frente à doença. Verificamos que o enfrentamento surgiu, em todas as etapas da doença, como forma de superar os tratamentos e os aspectos sociais que o câncer trás. Conclusão: A teoria construída neste estudo demostra que a mulher que vivencia o câncer de mama utiliza-se de aspectos de resiliência para enfrentar a sociedade, da família para oferecer suporte e de aspectos da experiência de vida. Este estudo contribui para impulsionar mudanças, transformações e inovações, tanto em nível pessoal, como profissional e institucional na assistência a essas mulheres.

Descritores: Neoplasias da mama; Diagnóstico; Enfermagem.

\section{ABSTRACT}

Objective: to know how women are diagnosed with breast cancer. Method: Qualitative study that used, as theoretical reference, the Symbolic Interactionism and, as methodological, the Theory Based on Data. We interviewed thirteen women in chemotherapy from a town in Minas Gerais in January 2014 and, after the analysis, came up the following the theory: "To experience breast cancer, it's necessary to be a confrontation". Results: the methodology allowed the discussion in three categories to debate the theory. They are: receiving the news about the diagnosis and the necessity for treatments; adaptation to treatment; previous experiences in the face of the disease. We verified that the confrontation arose in all stages of the disease as a way to overcome the treatments and the social aspects that the cancer brings. Conclusion: The theory constructed in this study shows that women who experience breast cancer need some resilience to face the society as a whole; family support; and some aspects of life experience. This study contributes to stimulate changes, transformations and innovations, both personally, professionally and institutionally, in these women care.

Descriptors: Breast neoplasms; Diagnosis; Nursing.

\section{RESUMEN}

Objetivo: conocer cómo las mujeres reciben el diagnóstico del cáncer de mama. Método: Estudio cualitativo que utilizó como referencial teórico el Interaccionismo Simbólico y, como metodológico, la Teoría Fundamentada en Datos. Se entrevistaron a trece mujeres en quimioterapia de un municipio minero, en el mes de enero de 2014 y, tras el análisis, surgió la teoría "Para vivir el cáncer de mama es necesario que haya un enfrentamiento". Resultados: la metodología permitió la discusión en tres categorías para debate de la teoría. Son ellas: recibiendo la noticia del diagnóstico y de la necesidad de los tratamientos; adaptación al tratamiento; experiencias anteriores frente a la enfermedad. Verificamos que el enfrentamiento surgió en todas las etapas de la enfermedad como forma de superar los tratamientos y los aspectos sociales que el cáncer aporta. Conclusión: La teoría construida en este estudio demuestra que la mujer que vive el cáncer de mama utiliza la resiliencia para enfrentar la sociedad; la familia para el soporte; y los aspectos de la experiencia de vida. Este estudio contribuye a impulsar cambios, transformaciones e innovaciones, tanto a nivel personal, como profesional e institucional en la asistencia a esas mujeres

Descriptores: Neoplasias de la mama; Diagnóstico; Enfermería.

${ }^{1}$ Graduada em Enfermagem. Mestra em Enfermagem pela Universidade Federal de Alfenas. ${ }^{2}$ Graduada em Enfermagem. Doutora em Ciências pela Escola de Enfermagem de Ribeirão Preto. ${ }^{3}$ Graduada em Enfermagem. PhD em Enfermagem, Universidade Federal de Alfenas.

Como citar este artigo:

Reis APA, Panobianco MS, Gradim CVC. Enfrentamento de mulheres que vivenciaram o câncer de mama. Revista de Enfermagem do Centro Oeste Mineiro. 2019;9:e2758. [Access___ Available in:__. DOI: http://dx.doi.org/10.19175/recom.v9i0.2758 


\section{INTRODUÇÃO}

A descoberta do câncer de mama, especialmente para as mulheres, é repleta de significados, visto que a doença e seus tratamentos promovem uma série de transformações na vida daquelas que o recebem, alterando seu corpo, o seu estado emocional e sua rotina de vida ${ }^{(1)}$.

No entanto, como o tratamento abrange um longo período de tempo, cerca de doze meses, esses sentimentos podem ir modificando frente a cada etapa da terapêutica, da reação do corpo, do apoio familiar, entre outros fatores. Assim, o acompanhamento durante todo o tratamento, pela equipe de saúde, permite reconhecer as necessidades dessas mulheres e interferir, de modo que essa fase transcorra com suporte ${ }^{(2)}$.

Entre as várias etapas do tratamento, a fase da quimioterapia é tida como uma das mais difíceis. Esse tratamento, apesar de ser de grande valia na recuperação da mulher com câncer, pode provocar, entre tantos efeitos colaterais, náuseas, vômitos, mucosites; pode provocar mudanças corporais como a alopecia e o ganho de peso; pode levar à falência ovariana, com decréscimo dos hormônios testosterona e estrógeno, induzindo à menopausa e implicando em atrofia vaginal, diminuição da lubrificação vaginal, da libido, anorgasmia e dispareunia, interferindo, dessa forma, na sexualidade. Pode, dessa forma, revelar à sociedade, a doença e a pessoa adoecida, fazendo com que a mulher tenha de enfrentar os diversos julgamentos valorativos atribuídos à quimioterapia pela população leiga. Além desses fatores físicos, a mulher convive com sentimentos de finitude e de dó ${ }^{(3-5)}$.

Assim, surge a inquietude: Como o diagnóstico de câncer de mama pode afetar o cotidiano da mulher? Na busca por respostas a esse questionamento, propôs-se o desenvolvimento deste estudo, que teve por objetivo, conhecer como as mulheres recebem o diagnóstico do câncer de mama.

\section{MÉTODOS}

Estudo de abordagem qualitativa que utilizou, como referencial teórico, o Interacionismo Simbólico (IS), que se preocupa em interpretar e compreender aspectos internos da conduta humana, ou seja, a maneira pela qual as pessoas percebem os fatos ou realidade à sua volta e como agem em relação às suas convicções, permitindo que pesquisadores ou profissionais de saúde estabeleçam juízo de valor ao fenômeno investigado ${ }^{(2)}$.

Para a compreensão da perspectiva teórica do IS, faz-se necessário a apreensão de conceitos pertinentes à sua interação, tais como mente, self, símbolos, interação social e sociedade, descritos por Mead e explicados por Blumer em $1937^{(6)}$.

O self - o ego/a própria pessoa - é o elemento com o qual agimos; os símbolos são usados com a intenção de comunicação entre indivíduos e do indivíduo consigo mesmo; a comunicação se faz por meio de símbolos e, a partir da interpretação dos mesmos, faz-se a interação social; por fim, a sociedade é caracterizada como dinâmica, os indivíduos interagem, definindo e alterando a direção de seus atos ${ }^{(6)}$.

O Interacionismo Simbólico fundamenta-se em três premissas: o sentido que as coisas têm para o ser humano; as coisas passam a ter um sentido para ele a partir da interpretação que ele faz delas; e o sentido que as coisas têm para ele devido à sua interação com o outro. Isso possibilita um conhecimento baseado na realidade do sujeito, a partir da interação que ele faz consigo próprio e com os outros, considerando o que acontece no presente ${ }^{(2,6)}$.

Já o referencial metodológico adotado foi a Teoria Fundamentada em Dados (TFD), que enfatiza a importância de se conhecer, entender e interpretar a natureza de eventos e situações, quer sejam eles passados ou presentes ${ }^{(7)}$. A Teoria Fundamentada em Dados foi desenvolvida pelos sociólogos Barney G. Glaser e Anselm L. Strauss, no início da década de $1960^{(8)}$. Embora Glaser e Strauss tenham originado e desenvolvido, juntos, a Grounded Theory, posteriormente, eles assumiram caminhos diferentes. Assim, o presente estudo foi orientado pelas concepções de Strauss e Corbin.

A TFD permite uma sistematização técnica e procedimentos de coleta e de análise que capacitam o pesquisador para desenvolver teorias sociológicas sobre o mundo de vida dos indivíduos, uma vez que alcança significação, compatibilidade entre teoria e observação, capacidade de generalização e de reprodutibilidade, de precisão, de rigor e de verificação ${ }^{(8)}$.

Nesse método, a análise dos dados é realizada por meio do processo de codificação dos dados e ocorre através de três fases distintas, mas complementares e integradas: a codificação 
aberta, axial e seletiva. Assim, a TFD tem o propósito de construir um modelo teórico que facilite o entendimento dos fenômenos sociais a partir da perspectiva dos sujeitos investigados e, os dados categorizados são representados por meio de diagramas e de quadros, o que facilita a reflexão dos mesmos ${ }^{(7)}$.

De acordo com a TFD, os dados foram organizados manualmente $\mathrm{e}$, respeitando as etapas propostas pela TDF, entrevista realizada é entrevista transcrita e analisada. Após a transcrição de cada entrevista, foi realizada leitura minuciosa e atenta das palavras, frases e linhas com o intuito de verificar os códigos abertos, primeira etapa do processo de análise dos dados, chamada de codificação aberta e, assim, foram selecionado trechos da entrevista que retratassem a essência do relato da depoente $^{(7)}$.

Após essa etapa, nova leitura era realizada, agora com foco nos códigos abertos. Esse processo, segunda etapa da análise dos dados, denominada de codificação axial, permitiu a aproximação dos fatos sociais, contribuindo para o conhecimento e reflexão sobre os dados que emergiam. Essa análise possibilitou agrupar os códigos semelhantes em subcategorias e categorias. Por fim, foi realizada a terceira e última etapa do processo de análise dos dados, chamada de codificação seletiva, com o objetivo de refinar e integrar categorias, desvelando uma categoria que fosse central, que incluísse todas as demais, fazendo emergir a teoria do estudo, a teoria fundamentada, que foi definida como: "Para vivenciar o câncer de mama tem que existir enfrentamento".

O presente estudo foi desenvolvido em um serviço de oncologia de um município mineiro, na região do sul de Minas Gerais. As atrizes sociais foram mulheres que tiveram o diagnóstico de câncer de mama e estavam na fase do tratamento da quimioterapia, momento em que foi realizada a coleta de dados. Os critérios de inclusão estabelecidos foram: ser mulher, ter tido diagnóstico de câncer de mama, ter realizado tratamento cirúrgico para a remoção do tumor e estar realizando tratamento quimioterápico. 0 critério de exclusão foi: mulheres que estivessem em tratamento paliativo.

A amostra final ficou composta por 13 atrizes sociais e o critério para o encerramento das entrevistas foi a compreensão do objeto de estudo e repetição de informações. A coleta de dados foi realizada no período de 08 a 29 de janeiro de 2014, por meio de entrevista gravada, tendo como pergunta norteadora: "Como foi para você receber o diagnóstico do câncer de mama?"

As mulheres foram abordadas e convidadas a participar da pesquisa e, mediante a concordância, o Termo de Consentimento Livre e Esclarecido foi assinado em duas vias, sendo uma das vias, entregue a elas. $O$ estudo foi encaminhado ao Comitê de Ética em Pesquisa (CEP) da Universidade Federal de Alfenas UNIFAL-MG, de acordo com a Resolução do Conselho Nacional de Saúde (CNS) no 466, de 12 de dezembro de 2012, e aprovado com o parecer no $478.376^{(9)}$.

\section{RESULTADOS E DISCUSSÃO}

Com o intuito de fornecer mais informações acerca das participantes da pesquisa, aqui são apresentados os dados socioeconômicos e da patologia delas, coletados da entrevista, do prontuário e dos registros no diário de campo. Para a garantia do sigilo dos dados e dos nomes das mulheres, elas foram identificadas com a letra $E$ de entrevista e do número correspondente à ordem que as mesmas ocorreram, como é demostrando no Quadro 1.

Quadro 1 - Dados socioeconômicos e da patologia das atrizes sociais. Passos-MG, 2015.

\begin{tabular}{|c|c|c|c|c|c|c|}
\hline Entrevista & $\begin{array}{l}\text { Idade em } \\
\text { anos }\end{array}$ & Estado civil & Escolaridade & Profissão & $\begin{array}{l}\text { Lateralidade } \\
\text { da mama afetada }\end{array}$ & $\begin{array}{l}\text { Estágio do } \\
\text { câncer }\end{array}$ \\
\hline E1 & 43 & casada & $\begin{array}{l}\text { Fundamental } \\
\text { incompleto }\end{array}$ & Aposentada & Direita & $I I A$ \\
\hline E2 & 32 & casada & $\begin{array}{l}\text { E. Médio } \\
\text { Completo }\end{array}$ & Comerciante & Esquerda & IIB \\
\hline E3 & 60 & casada & Superior & Pedagoga & Direita & $\| A$ \\
\hline E4 & 39 & casada & $\begin{array}{l}\text { E. Médio } \\
\text { Completo }\end{array}$ & Do lar & Direita & $\| A$ \\
\hline E5 & 37 & casada & Superior & Autônoma & Direita & IIB \\
\hline
\end{tabular}




\begin{tabular}{|c|c|c|c|c|c|c|}
\hline E6 & 59 & viúva & Superior & Professora & Esquerda & $\| \mathrm{A}$ \\
\hline E7 & 61 & casada & $\begin{array}{l}\text { Fundamental } \\
\text { incompleto }\end{array}$ & $\begin{array}{l}\text { Empregada } \\
\text { doméstica }\end{array}$ & Esquerda & $\| \mathrm{A}$ \\
\hline E8 & 54 & casada & $\begin{array}{l}\text { Fundamental } \\
\text { incompleto }\end{array}$ & $\begin{array}{l}\text { Empregada } \\
\text { doméstica }\end{array}$ & Direita & IIIA \\
\hline E9 & 60 & casada & $\begin{array}{l}\text { Fundamental } \\
\text { completo }\end{array}$ & Comerciante & Direita & $\| \mathrm{A}$ \\
\hline E10 & 56 & divorciada & $\begin{array}{l}\text { Fundamental } \\
\text { incompleto }\end{array}$ & Lavradora & Esquerda & IIIA \\
\hline E11 & 50 & casada & $\begin{array}{l}\text { Fundamental } \\
\text { incompleto }\end{array}$ & Do lar & Esquerda & IIIB \\
\hline E12 & 50 & casada & Superior & Advogada & Esquerda & $\| \mathrm{A}$ \\
\hline E13 & 42 & solteira & $\begin{array}{l}\text { E. Médio } \\
\text { Completo }\end{array}$ & $\begin{array}{l}\text { Técnica de } \\
\text { enfermagem }\end{array}$ & Esquerda & $\| A$ \\
\hline
\end{tabular}

Fonte: Dados da pesquisa.

Os dados do quadro acima mostram que $38 \%$ das atrizes sociais tinham menos de 50 anos e que $23 \%$ delas apresentavam o câncer em estágio III. Como os dados foram coletados durante a quimioterapia, já eram esperados esses estágios mais avançados. A lateralidade da mama esquerda ocorreu em $54 \%$.

O fato de o estadiamento dos tumores que afetaram as participantes do presente estudo serem, em sua maioria, avançados, pode sugerir atraso na busca de serviço médico pela mulher ou ainda falhas na busca ativa realizada pelos serviços de atenção primária ${ }^{(10)}$.

Em relação à lateralidade da mama acometida, houve predomínio da esquerda e, dessa forma, os dados diferem dos de outras pesquisas que indicam que a mama direita costuma ser a mais acometida ${ }^{(11)}$.

Estudos recentes têm demonstrado uma preocupação crescente com o aparecimento de câncer em mulheres mais jovens, e este estudo mostra que, realmente, essas mulheres têm sido atingidas pela doença. Nesse sentido, é importante lembrar que o câncer de mama em mulheres jovens merece atenção especial, uma vez que é mais agressivo, geralmente descoberto em estágios mais avançados e, consequentemente, seus tratamentos são menos efetivos $^{(12)}$.

Após a análise das entrevistas, de acordo com a metodologia proposta, houve a criação do diagrama (Figura 1) que se refere aos dados categorizados.

Figura 1 - Diagrama: Enfrentamento do câncer de mama. Passos, 2015.

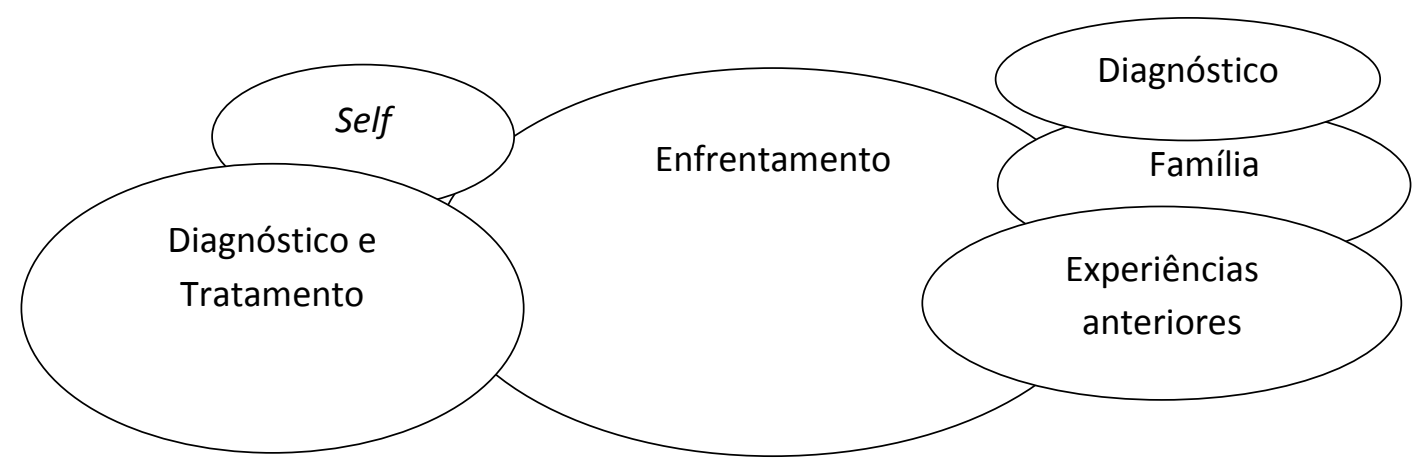

No diagrama acima (Figura 1), temos a categoria central, que gerou a Teoria Fundamentada em Dados: "Para vivenciar o câncer de mama é necessário que haja um enfrentamento". Esse enfrentamento foi ocorrendo gradativamente e, a partir do diagnóstico da doença, mostraram-se etapas que deram origem a três subcategorias: 1- Recebendo 
a notícia do diagnóstico e da necessidade dos tratamentos; 2- Adaptação ao tratamento; 3Experiências anteriores frente à doença.

\section{1 - Recebendo a notícia do Diagnóstico e da necessidade dos tratamentos}

O câncer de mama é temido em nossa sociedade, especialmente pelas mulheres, devido ao seu índice elevado de morbimortalidade e de mutilação, acarretando comprometimento da autoestima e do convívio social de quem é, por ele, acometido, pois interfere nas relações pessoais, sociais, afetivas e profissionais ${ }^{(13)}$.

Assim, quando a mulher recebe 0 diagnóstico de câncer de mama, tem crises de instabilidade emocional, marcadas por frustrações, conflitos, medos e insegurança. Esse sofrimento decorre do pensamento de possível morte e da associação do caráter incurável da doença. A confirmação do diagnóstico leva ao impacto na vida tanto da paciente quanto nas de seus familiares e o sentimento de perplexidade mostra-se presente ${ }^{(14)}$.

Em relação a isso, as mulheres aqui estudadas comentaram que, ao receber 0 diagnóstico de câncer de mama, depararam-se com algo que lhes parecia assustador, pois poderiam morrer a qualquer momento:

"Porque é igual eu estou te falando: câncer é assustador! Câncer é assustador! Qualquer pessoa que recebe esse diagnóstico é assustador. Então, para mim, ele é assustador. Para mim, ele é assustador, e para todo mundo!" (E9)

Assim, como explica o IS, a mulher, em sua relação consigo mesma, sentiu-se fragilizada diante de sua nova situação com o diagnóstico da doença, e se assustou diante da possibilidade de morte, pois é assim que o câncer na mama se mostrou a ela.

E essa sensação de fragilidade e impotência se reforça quando ela interpreta o significado do diagnóstico, em sua relação com os outros e com o mundo:

“Porque na cabeça das pessoas, elas acham assim (...) você está com câncer! Você está uma pessoa debilitada, está morrendo! Eles acham assim, que a gente está de cadeira de rodas (risos)." (E4)

Diante do diagnóstico de câncer, as mulheres o consideraram tanto em sua relação consigo mesmas como em sua relação com os outros e com o mundo, uma doença devastadora. Isso se confirmou diante do fato de o órgão acometido ser a mama, pois esse é um símbolo representativo de sua feminilidade e, no passo seguinte, ao entenderem a necessidade de tratar a doença, sua sensação de fragilidade e impotência aumentou pois, caso necessitassem de um procedimento cirúrgico ${ }^{(12)}$, poderiam perder a mama afetada.

"No início, eu tive muita dificuldade para aceitar ter que passar por esse tratamento e assim, cada etapa a gente tem medo de alguma coisa. A primeira foi a retirada da mama porque eu não reconstruí, reconstituí na hora não." (E5)

Nesse sentido, autores afirmam que a mama feminina tem um simbolismo social na sociedade ocidental. Os seios são considerados símbolo do feminino, visto que são responsáveis por proporcionar às mulheres sensações de prazer, além de estarem relacionados à sexualidade, fertilidade e maternidade ${ }^{(2)}$.

A necessidade de tratamento também reportou as mulheres a outras modalidades além da cirurgia, e elas se depararam com a possibilidade da quimioterapia, um tratamento que, geralmente, causa a queda dos cabelos e pelos do corpo e, assim, fere a vaidade feminina ${ }^{(15)}$.

Essa preocupação se deve ao fato de que, em nossa sociedade, os cabelos são tidos como fator de identidade feminina e espera-se que as mulheres os tenham longos e arrumados ${ }^{(16)}$.

Assim, as atrizes sociais deste estudo relataram que o diagnóstico de câncer de mama trouxe uma questão tripla: o medo de morrer, o sentimento de tristeza diante da perda da mama e a preocupação com a queda do cabelo, fato também encontrado em outro estudo ${ }^{(17)}$.

"Você fala que está com câncer, a primeira coisa que eles olham é se você tem peito! E olha para o cabelo para ver se caiu! É a coisa mais interessante!" (E3)

"Quando a notícia vem, você assusta! Aí, vem a cirurgia (...) é muito rápido. Vem a notícia, depois, você ainda vai tirar a mama, depois, já vem a quimioterapia. Então, não dá tempo muito de você raciocinar (...). Depois que vem a primeira quimio, que cai o cabelo, aí parece que você dá uma relaxada e fala: nossa (...) agora deixa eu respirar! Deixa eu pensar na minha vida! Porque, então, tudo é novidade. Depois, já não tem novidade mais, você já sabe mais ou menos o que te espera!" (E13)

Nessa primeira etapa, diante do terrível diagnóstico e da necessidade da realização dos tratamentos para o câncer, no sentido de evitar a finitude, as mulheres começam a mostrar indícios 
de que precisam enfrentar a batalha que se mostra à sua frente, diante da condição de portadoras do câncer de mama. E então, o enfrentamento do diagnóstico se dá com a realização dos tratamentos.

Os significados atribuídos por essas mulheres ao diagnóstico de câncer de mama revelam que o ser humano percebe a si mesmo e, assim, comunica-se consigo próprio, o que o faz objeto de sua própria ação. As mulheres exercem o conceito do self, quando reconhecem seus próprios conceitos e os conceitos que os outros têm dela. Assim, diante de determinadas situações, elas avaliam, observam, interpretam e formulam as ações individuais ou em conjunto e atuam frente ao objeto, no caso, o câncer de mama $^{(6)}$.

A partir da interpretação desses objetos e da reflexão dos mesmos por meio da fala e expressão corporal, isso se torna uma interação simbólica, e esses objetos transformam-se em símbolos.

“Pensar que primeiro Deus ajuda! A gente mesmo que nos ajuda; pensando que vai ser curada. Não desanimar nunca! Não deixar abater e falar assim (...) não vou ficar mal, não vou pensar que vou morrer, pensar que ainda vou viver muitos anos." (E1)

"Mas eu, nem com a notícia quando o médico disse para mim é carcinoma tal, tal, tal... você vai ter que fazer quimioterapia, vai ter que fazer uma cirurgia e tem que ser rápido! Falei: meu Deus! Será que eu tenho que chorar? (...) sabe, não sei se é porque eu já perdi uma filha de dezenove anos... então, depois que você sente essa dor, as outras, sabe, você (...) sei lá, não sei se a gente vai ficando frio sabe (pausa) não sei se é isso (...) mas não me assustei com a notícia." (E12)

Os relatos indicam que as mulheres possuem consciência da gravidade de sua doença, porém a percepção de que devem enfrentar o problema se faz presente e a cura se torna sua principal meta e a crença religiosa se torna uma alternativa para buscarem o enfrentamento para o tratamento.

Quando essas mulheres vivenciaram perdas que geraram sofrimento, como a perda de um filho ou de um ente querido na família, percebe-se que a mulher desenvolve a resiliência. Esta é definida como as potencialidades e os recursos pessoais que possibilitam 0 enfrentamento de situações adversas e como o indivíduo pode sair dessas circunstancias mais fortalecido apesar da exposição a fatores de risco $^{(18)}$.

A mulher com câncer de mama se vira em direção ao seu self, em que o "eu" pode ser descrito como a dificuldade de se olhar no espelho e ver que não possui uma mama e que está careca, e o "mim", refere-se à sua autoimagem e autoestima, por meio de seus pensamentos, quando verifica seu reflexo no espelho, ou seja, como a mulher se autoanalisa após ver a imagem de um corpo mutilado e um rosto desfigurado devido à falta do cabelo.

Nesse sentido, a mulher passa a construir um novo self para dar conta dessa experiência e se apoia em fatores da sociedade para se firmar com uma nova autoimagem. Para superar essa situação, a mulher apoia-se na religiosidade e em experiências anteriores de sofrimento para transpor as adversidades e continuar seguindo em frente.

\section{2 - Adaptação ao tratamento}

Adaptar-se ao tratamento do câncer de mama é difícil, visto que, se tudo ocorrer bem, a mulher ficará o primeiro ano sob terapêutica, seja em cirurgia, em quimioterapia, em radioterapia ou terapia hormonal, sendo os procedimentos isolados ou em associação.

Durante o período inicial do tratamento, o primeiro ano, a mulher enfrenta uma série de transformações, tanto no seu corpo, quanto em sua vida de um modo geral. Em cada etapa do tratamento, verifica-se um tipo de sofrimento físico e psíquico que acomete essas mulheres, pois, primeiramente, elas enfrentam a mutilação da mama, uma parte do corpo valorizada pela mulher e, depois, em decorrência do tratamento quimioterápico, ocorre a queda do cabelo e/ou dos pelos do corpo.

Assim, o tratamento do câncer de mama pode produzir variados sentimentos e emoções, derivando em várias dificuldades que podem diminuir a adesão ao tratamento, uma vez que esse é um dos passos para o enfrentamento da doença que se inicia no momento do diagnóstico ${ }^{(13)}$.

"É mais difícil as perdas durante o tratamento do que o tratamento em si. Desde maio que eu estou tratando e nisso já perdi a mama, depois o cabelo (...) então, eu acho que essa é a parte mais difícil (...) as perdas durante o tratamento!" (E2)

"São várias etapas: a primeira foi aquela parte de papelada de exame, aquilo lá parece que 
é um (...) vira a gente do avesso aquele monte de coisa (...) agora é a fase nova que é vai ser a bendita." (E6)

Entretanto, algumas mulheres tentam não sofrer por antecedência, no intuito de amenizar a angústia e a ansiedade, mas se sabe que isso nem sempre é possível e que as incertezas em relação ao tratamento são muitas.

"Eu estou vendo, assim, que todas as etapas que eu estou passando, têm sido mais fáceis do que a gente imagina, então um conselho que eu sigo de uma publicação que eu li é assim (...) não sofrer por antecedência, então eu estou procurando fazer isso!" (E5)

"Eu falo que essa doença não é difícil, o difícil é o limite dela!" (E9)

As sequelas advindas do tratamento do câncer de mama precisam ser mensuradas em relação às limitações físicas e psicológicas provocadas na paciente e os profissionais de saúde precisar estar atentos ao impacto da doença e de seu tratamento sobre a qualidade de vidas dessas mulheres. Observa-se que existem poucos programas disponíveis para a reabilitação física e psicológica da mulher com câncer de mama. Aliado a isso, há ainda os fatores de dificuldade de locomoção por motivos financeiros ou de ordem operacional, o que levam as mulheres a encontrarem dificuldade de acesso a profissionais especializados para auxiliar em seu processo de reabilitação ${ }^{(19)}$.

No tratamento para o câncer de mama, as alterações físicas não se esgotam com a perda da mama. Existe também o comprometimento do braço homolateral à mama, em consequência da retirada de parte ou de toda a rede linfática, o que leva à diminuição da drenagem da linfa e acúmulo da mesma, neste braço, o que dificulta e causa limitações nos movimentos.

"Tem dia, final do dia mesmo, parece que eu estou com uma bola debaixo do braço." (E4)

"Limite dela (da doença)! Olha para esse braço (...) não posso fazer nada com ele; que ele incha. Não posso deixar machucar, não posso (...) então, é o limite dela que dá a limitação para você, o difícil é isso (...) você aceitar." (E9)

"Só que, graças a Deus, eu sinto bem, só o que eu sinto mesmo é a dor no braço, porque o braço não pode mexer (...) eu mexo, ele perde a força, e aqui oh (...) parece que tem um caroço, parece que bateu assim, aí qualquer coisinha que esbarra, aí eu choro de dor." (E10)

Esse fato leva a alterações no cotidiano dentro do convívio familiar, uma vez que a mulher passa a ter dificuldades para a realização dos afazeres domésticos, considerados pelo grupo como de sua responsabilidade, pois são inerentes à figura feminina dentro do lar. Assim, começam as alterações de estrutura familiar e, muitas das tarefas, antes executadas por essas mulheres, passam a ser realizadas por outros membros da família ${ }^{(20)}$.

"Eu tenho uma pessoa que está passando roupa para mim e, às vezes, a roupa que dá para passar, dos meninos, eu passo com essa mão aqui para não forçar essa que eu estou fazendo fisioterapia." (E4)

"É porque todo mundo trabalhava, eu estava com saúde, todo mundo chegava já estava tudo pronto! (...) eles não faziam nem café nem nada, chegava em casa estava tudo arrumadinho, então, todo mundo ficava tranquilo, agora, todo mundo caiu na dança!" (E8)

Não é apenas o movimento do braço que se altera. Outros cuidados também precisam ser incorporados ao cotidiano da mulher como, por exemplo, evitar a exposição ao sol ou se manter longe do calor do fogo, tomar cuidado para não se machucar ou cortar, não fazer esforço, não carregar peso e não realizar movimentos repetitivos com o braço afetado. Frente a isso, os aspectos do cotidiano passam a ter limitações que interferem na habilidade dos afazeres domésticos e que podem levar a aspectos subjetivos, provocando mal-estar pela sensação de limitação, de déficit de autonomia ${ }^{(21)}$.

"Eu fazia de tudo! Eu vendia móveis, fazia almoço, fazia janta, fazia (...) na minha loja mesmo, eu fazia o almoço, eles iam todos almoçar lá comigo!" (E9)

"Tem dia que eu choro é de nervoso de ver o serviço e não poder fazer. Mas não adianta chorar, o serviço tem que ficar!" (E10)

A diminuição do movimento acaba por interferir na execução das atividades diárias, o que gera desconforto para dormir e dirigir, distúrbios na postura, redução da capacidade para os trabalhos físicos e habilidade diminuída para a realização dos afazeres domésticos. Essas limitações geram desconfortos psicológicos para as mulheres, pois retratam, constantemente, a presença da doença e a possibilidade da não recuperação da capacidade plena. Assim, o tratamento do câncer é vivenciado como o responsável pelas alterações permanentes em sua vida que, mesmo com o término do tratamento, os incômodos persistem, demandando enfrentamento constante ${ }^{(22)}$. 
A impossibilidade de trabalhar é algo que intimida e marginaliza, uma vez que o trabalho é uma das maneiras pelas quais o ser humano se expressa, realiza-se e identifica-se enquanto ser no mundo. A incapacidade física, para desenvolver as atividades cotidianas de trabalho, implicam sentimentos que deprimem a qualidade de vida do indivíduo.

Tudo isso, no entanto, precisou de uma adaptação das mulheres para que elas pudessem continuar vivendo e vivenciando a doença e realizando os tratamentos, de modo a buscar a cura, mesmo que, para isso, tivessem de sofrer com todos efeitos deletérios. Nesta etapa, portanto, o enfrentamento se deu por meio da adaptação aos tratamentos realizados para o câncer de mama.

\section{3 - Experiências anteriores frente à doença}

O período da terapêutica pode acarretar em efeitos positivos ou negativos na paciente e nos membros da família, pois eles podem apresentar sentimentos de proteção, de preocupação, de ansiedade, de raiva e de culpa frente ao tratamento da familiar doente.

As mulheres relatam que seu enfrentamento em relação à doença foi positivo. $\mathrm{Se}$, anteriormente, elas tiveram uma experiência boa em relação à doença, como no caso em que alguém da família ou do convívio que teve câncer, recuperou-se e goza de boa saúde. Nos casos em que a mulher teve experiências que levaram um ente querido ou amigos à morte, estas encaram a doença como algo extremamente negativo em suas vidas.

"Eu penso muito na minha irmã. O da minha irmã foi muito agressivo, minha irmã mais velha. Ela tirou muito, mas foi muito mesmo e do braço. $O$ dela tinha cinco centímetros. Era mais avançado (...). E pelo dela, eu acho que eu animei mais com o meu (...) eu falei assim (...), gente, se o dela foi tão grande e agressivo, se ela passou por isso e está aí tranquila. O meu pequeninho desse jeito e ainda não vou tirar nem a mama, nem nada, não tem pelo braço, nem nada. Então eu falei assim: não é possível que eu não vou vencer!" (E3)

"A experiência que eu tive com o meu marido não foi boa porque ele acabou falecendo." (E6)

Em relação às consequências do tratamento quimioterápico, como a alopecia, esta foi encarada de modo mais tranquilo quando essas mulheres experienciaram situações anteriores ao seu diagnóstico.

“Não, não assustei não (...) eu falei assim (...) isso aí vai cair mesmo, eu já tinha visto a minha irmã. $O$ dela nasceu forte de novo, bonito, um cabelo bonito. Foi normal, eu já sabia, eu já vi outras pessoas que fez tratamento e caiu o cabelo, aí eu não assustei." (E1)

Para aquela mulher que vivenciou anteriormente uma experiência de queda de cabelo advinda do tratamento quimioterápico, essa situação é encarada de maneira mais tranquila, uma vez que conhece as etapas do tratamento e sabe que, para vencer a doença, é necessário enfrentar os obstáculos e superar as adversidades. A queda do cabelo é um evento passageiro e necessário para a cura da neoplasia.

Estudos demonstram ${ }^{(20,23)}$, assim como este, que $o$ apoio dos familiares nesse momento foi fundamental para que a mulher enfrente a situação e para que esse período do tratamento transcorra do modo mais tranquilo possível.

Além dos familiares, a equipe de enfermagem e os grupos de apoio também podem servir de suporte às pessoas que vivenciam o problema estudado ${ }^{(2)}$.

No período da quimioterapia, a enfermagem possui contato direto com a mulher e deve estar atenta aos sentimentos que relata sobre os efeitos colaterais, além de orientá-la sobre o cuidado com os cabelos no que se refere à alopecia. Isso é importante, porque a queda de cabelos ocorre normalmente após a segunda sessão e essa queda é brusca, ou seja, ele não cai vagarosamente e, sim, de um dia para o outro ${ }^{(2)}$.

Assim, faz-se necessário orientar a mulher sobre as perdas ocasionadas pelo tratamento quimioterápico, pois se considera que a informação antecipada pode diminuir o impacto no momento em que a queda do cabelo e dos pelos do corpo se inicia.

Quando a enfermagem exerce seu papel de orientação efetiva, o enfrentamento da mulher pode ser positivo e, quando isso ocorre, a mulher cria alternativas, como o uso de lenços, perucas, gorros, chapéus, entre outros.

Mas, em casos que esse enfrentamento é negativo, ela tende a se esconder, para não se mostrar doente. Essa não aceitação pode interferir no sistema imunitário, levando-a enfrentar um ciclo de desânimo em cada sessão da quimioterapia e, muitas vezes, até desistindo do tratamento ${ }^{(24)}$. 
Assim, utilizando a metodologia proposta, a TFD chega à teoria de que vivenciar o câncer de mama leva a sentimentos que vão da incompreensão do porquê da doença às ações de aceitação de ter que passar por isso, reforçando a importância de o atendimento a essas mulheres ser individualizado. Isso porque os medos e os enfrentamentos são diferentes frente ao câncer e que são fatores que vão ser percebidos dependo da escolaridade, da experiência anterior e do suporte familiar e dos profissionais de saúde.

Observa-se que há necessidade de aprofundamento nos estudos sobre esta problemática com a ampliação da amostra e repetição em outros locais, pois essa é a fase crítica do tratamento e que a mulher tem contato com os profissionais de saúde, principalmente o enfermeiro, que pode auxiliar nas dúvidas e permitir que a mesma passe esse período com menos sofrimento.

\section{CONSIDERAÇÕES FINAIS}

Apesar de o conhecimento sobre o câncer ser uma problemática que vem sendo discutida com maior ênfase nos últimos anos, este estudo permitiu refletir sobre o enfrentamento das mulheres que tiveram um diagnóstico de câncer de mama e constatar que esta é a ação mais presente nesse grupo de mulheres. Elas relataram que tiveram sentimentos conflitantes e que o apoio familiar permitiu que o enfretamento, durante $o$ tratamento, fosse positivo e desenvolveram resiliência frente a ele.

A teoria construída neste estudo nos permite compreender melhor a realidade $\mathrm{e}$ desperta para uma reflexão e análise crítica acerca da mesma, o que leva a evitar a naturalização e a banalização dos fenômenos, pois inclui elementos científicos que proporcionam a análise e o entendimento da realidade e, também, contribui para mudanças, transformações e inovações, tanto em nível pessoal, como profissional e institucional.

Esperamos que os resultados subsidiem o trabalho de profissionais que prestam assistência às mulheres com câncer de mama e que os mesmos considerem, durante o atendimento, que devem questionar aspectos que podem gerar sofrimento frente à doença e seu tratamento e que, além de orientá-las, encaminhem-nas para os grupos de apoio.

\section{REFERÊNCIAS}

1- Machado MX, Soares DA, Oliveira SB.
Significados do câncer de mama para mulheres no contexto do tratamento quimioterápico. Physis 2017;27(3):433-51. DOI: 10.1590/S010373312017000300004

2- Reis APA. Alopecia: Cotidiano da mulher com câncer de mama em tratamento quimioterápico [dissertação]. Alfenas (MG): Universidade Federal de Alfenas; 2015.

3- Santos DB, Santos MA, Vieira EM. Sexualidade e câncer de mama: Uma revisão sistemática da literatura. Saúde Soc. 2014;23(4):1342-55. DOI: 10.1590/S0104-12902014000400018

4- Machado MX, Soares DA, Oliveira SB. Significados do câncer de mama para mulheres no contexto do tratamento quimioterápico. Physis 2017;27(3):433-51. DOI: 10.1590/S010373312017000300004

5- Oliveira KD, Oselame GB, Neves EB. Infertilidade após o tratamento oncológico. Rev Med Saúde 2014 [citado em 5 dez 2018]; 3(1):72$84 . \quad$ Available in: http://portalrevistas.ucb.br/index.php/rmsbr/arti cle/viewFile/4898/3140

6- Blumer H. A natureza do Interacionismo simbólico. In: MORTENSEN CD. Teoria de comunicação: Textos básicos. São Paulo: Mosaico; 1980.

7- Strauss A, Corbin J. Técnicas e procedimentos para o desenvolvimento de teoria fundamentada. 2a ed. Porto Alegre: Artmed; 2008.

8- Gomes IM, Hermann AP, Wolff LDG, Peres AM, Lacerda MR. Grounded theory in nursing: An integrative review. J Nurs UFPE 2014;9(1):466-74. DOI: 10.5205/1981-8963-v9i1a10360p466-474$\underline{2015}$

9- Brasil. Conselho Nacional de Saúde. Resolução no 466, de 12 de dezembro de 2012. Dispõe sobre diretrizes e normas regulamentadora de pesquisas envolvendo seres humanos. Diário Oicial da União 2013;1:59.

10- Rodrigues JD, Cruz MS, Paixão AL. Uma análise da prevenção do câncer de mama no Brasil. Ciênc Saúde Colet. 2015;20(10):3163-76. DOI: 10.1590/1413-812320152010.20822014

11- Alves MO, Magalhães SCM, Coelho BA. Health regionalization and assistance to users with breast cancer. Saúde Soc. 2017;26(1):141-54. DOI: 10.1590/s0104-12902017160663

12- Barros AF, Uemura G, Macedo JLS. Interval for access to treatment for breast cancer in the Federal District, Brazil. Rev Bras Ginecol Obstet. 2013;35(10):458-63. DOI: $10.1590 /$ S0100$\underline{72032013001000006}$ 
13- Mineo FLV, Matos LFB, Lima SS, Deluque AL, Ferrari R. Assistência de Enfermagem no tratamento do câncer de mama. Revista Gestão \& Saúde 2013 [citado em 24 jan 2018]; 4(2):366-88. Available in: http://gestaoesaude.unb.br/index.php/gestaoesa ude/article/view/279/pdf

14- Gontijo IBR, Ferreira CB. Sentimentos de mulheres jovens frente ao diagnóstico de câncer de mama feminino. Ciênc Saúde 2014;7(1):2-10. DOI: 10.15448/1983-652X.2014.1.15488

15- Coelho RCFP, Panobianco MS, Guimarães PRB, Maftum MA, Santos PND, Kalinke LP. Adjuvant and neo adjuvant chemotherapy and the implications in the quality of life women with breast cancer. J Nurs UFPE 2017;11(suppl 11):4732-40. DOI: 10.5205/reuol.11138-99362-1SM.1111sup201725

16- Reis APA, Gradim CVC. Alopecia in breast cancer. J Nurs UFPE 2018;12(2):447-55. DOI: 10.5205/1981-8963-v12i2a25097p447-455-2018

17- Carvalho CMS, Amorim FCM, Silva RTS, Alves VF, Oliveira ADS, Monte NS. Feelings of women diagnosed with breast cancer. J Nurs UFPE 2016; 10(11):3942-50. DOI: 10.5205/1981-8963v10i11a11476p3942-3950-2016

18- Matos F, Martins $H$, Jesus SN, Viseu J. Prevenção da violência através da resiliência dos alunos. Psic, Saúde \& Doenças 2015;16(1):35-43. DOI: $10.15309 / 15 p s d 160105$

19- Oliveira GF, Ribeiro STM. Sentimento da mulher após diagnóstico de câncer de mama: Uma revisão integrativa da literatura. Voos Revista Polidisciplinar Eletrônica da Faculdade Guairacá 2011 [citado em 24 jan 2018]; 3(2):6881. Available in:

http://www.revistavoos.com.br/seer/index.php/v oos/article/view/228/06 Vol3.2 VoOS2011 CCS 20- Gómez CEP, Sánchez LVG, Enríquez JI. Experiencias de vida en mujeres con cáncer de mama en quimioterapia. Rev Colomb Psiquiat. 2011 [citado em 5 dez 2018]; 40(1):65-84. Available in: https://www.sciencedirect.com/science/article/pi i/S0034745014601050

21- Rodrigues AC. Alterações de desempenho ocupacional e papéis ocupacionais de mulheres com câncer de mama: Uma revisão integrada da literatura [trabalho de conclusão de curso]. Brasília: Universidade de Brasília; 2014.

22- Ribeiro IFA, Sousa RDF, Andrade SP, Brito MCC, Albuquerque IMN. Grupo de autoajuda com mulheres mastectomizadas: Trabalhando estratégias de educação em saúde. Sanare 2014 [citado em 24 jan 2018]; 13(1):35-40. Available in: https://sanare.emnuvens.com.br/sanare/article/v iew/430/285

23- Oliveira MR, Mattias SR, Santos IDL, Pinto KRTF, Gomes NCC, Cestari MEW. A família diante do diagnóstico de câncer de mama sob o olhar da mulher. Rev Pesqui Cuid Fudam. 2018 [citado em 5 dez 2018]; 10(4):932-5. Available in: file://C:/Users/POSITIVO/Downloads/626738779-1-PB.pdf

24- Peña CG. Enfrentando o câncer: Cuidados com a imagem pessoal. São Paulo: Senac; 2013.

Nota: Artigo resultante de pesquisa de dissertação.

Recebido em: 02/02/2018

Aprovado em: 13/12/2018

Endereço de correspondência:

Ana Paula Alonso Reis Mairink

Estrada de Muzambinho-Km 35, Morro Preto CEP: 37890-000 - Muzambinho/MG - Brasil

E-mail: ana.reis@muz.ifsuldeminas.edu.br 